\title{
Infra-Through Ultrasonic Piezoelectric Acoustic Vector Sensor Particle Rejection System
}

\author{
Scott E. Cravens and Ronald M. Barrett \\ Aerospace Engineering Department, University of Kansas, Lawrence, KS 66045, USA \\ Correspondence should be addressed to Ronald M. Barrett, barrettr@ku.edu \\ Received 15 November 2011; Accepted 16 January 2012 \\ Academic Editor: Tao Li
}

Copyright ( $) 2012$ S. E. Cravens and R. M. Barrett. This is an open access article distributed under the Creative Commons Attribution License, which permits unrestricted use, distribution, and reproduction in any medium, provided the original work is properly cited.

\begin{abstract}
Sensor elements which employ fine filaments are often vulnerable to particulate fouling when used in certain operational field conditions. Depending on the size, attraction level, thermal and electrical conduction, and charge accumulation properties of the particles, erroneous readings can be easily generated in such "dirty" environments. This paper describes the design, development, and testing of an ultrasonic system which dynamically rejects highly tenacious electrostatically charged particles of a wide variety of sizes and even water. The paper starts with a brief introduction to the field of acoustic vector sensing, outlining its outstanding characteristics and history. Operational challenges including a statistical analysis of typical Middle-Eastern wind-blown desert sand and charge density are laid out. Several representative subscale hot-wire filaments were fouled with calibrated dust representing desert sand. The fouled elements were then exposed to airflows of $13 \mathrm{ft} / \mathrm{s}(4 \mathrm{~m} / \mathrm{s})$ and showed highly erratic shifted conduction levels with respect to baseline (clean) levels. An ultrasonic cleaning system was designed specifically resonate the filament and cantilever so as to mechanically reject foulants. When operated at resonance, the ultrasonic cleaning system showed $98.6 \%$ particulate rejection levels and associated restoration of uncorrupted filament resistance levels to within $2 \%$ of baseline resistance measurements.
\end{abstract}

\section{Introduction}

Over the past decade, a new class of acoustic sensors has evolved. Conventional microphone technologies simply measure pressure as a function of time. These scalar measuring devices must be used in sizable clusters with powerful computers detangling this limited information [1]. A new approach using acoustic vector sensors (AVSs) employs fundamentally different sensor physics. These AVS elements are capable of not only determining pressure as a function of time (as do conventional microphones), but they can divide acoustic source directionality by measuring particle velocity in $x, y$, and $z$ coordinates with time at very high rates and phenomenal dynamic range [2]. Acoustic vector sensors use a number of different techniques to determine acoustic source direction. One of the leading acoustic vector sensors employs an advanced dual hot-wire anemometry setup to measure particle movement in multiple directions. The device is used in many applications ranging from acoustic holography to tracking airborne vehicles as well as aquatic applications. Most of the applications currently employing these AVS devices are limited to clean environments, meaning free of dust particles, and other small environmental debris. Testing in dirty environments is limited at best to date. Fouling by particulate adherence or even complete particle blockage of measurement channels is a very distinct possibility given the small scale of the devices. The primary vulnerability comes from the very geometry and size of the sensor filaments which when compared to the size of airborne particulates are such that the largest airborne particles are an exact fit between the substrate and the sensor elements, which indicates that the devices could actually "trap" airborne particles. Figure 1 shows an interesting comparison of typical Appalachian quartz-based beach sand and sand from the Ash Shuqqan in the Empty Quarter (Rub al Khali) of the Arabian Peninsula.

The reader will note a profound difference between the two types of sand as the beach sand is quite rounded and 


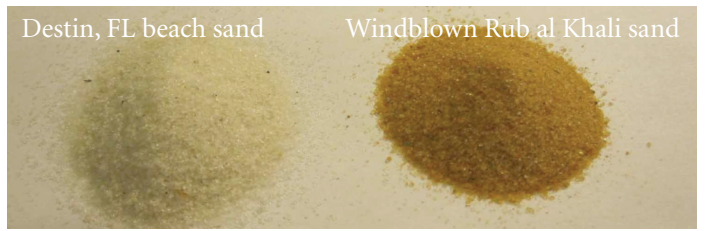

Figure 1: Beach sand from Destin, Florida (for reference) and windblown sand from the Rub al Khali, Arabian Peninsula.

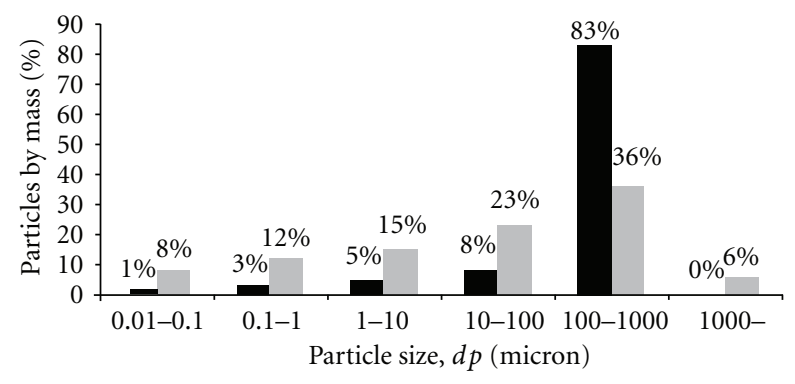

- Destin, FL

Rub al Khali

Figure 2: Particulate sand size distribution by percentage of sample mass of beach sand and Middle-Eastern windblown sand.

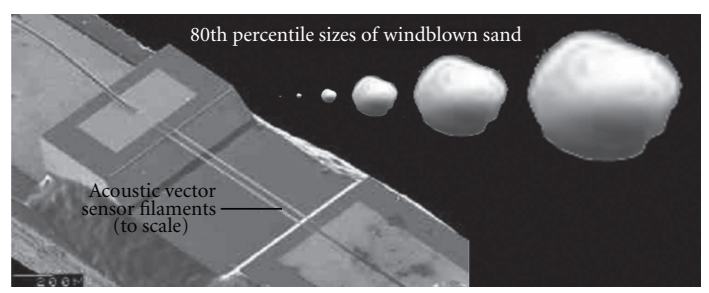

FIgURE 3: Advanced AVS sensing wires [2].

fairly even in size distribution with more than $80 \%$ of the grains falling between 130 and $640 \mu \mathrm{m}$ in diameter. The wind blown sand, on the other hand, is quite different with a wide distribution of sizes ranging widely from less than $1 \mu \mathrm{m}$ to $1100 \mu \mathrm{m}$ in diameter in statistically significant numbers by weight and volume. Another interesting characteristic is also seen in Figure 1: Static electric attraction. Wind blown sand from the Arabian Peninsula on the other hand behaves very differently and possesses different properties. Because most beach sand has been completely coated by salt water for a very long time, it is more resistant to holding large static charges. Indeed, single grain electrical resistance levels in $30 \%$ humidity were measured at $300-500 \Omega / \mathrm{mm}$ for the beach sand and more than $20 \mathrm{M} \Omega / \mathrm{mm}$ for the wind blown sand. Similarly, the capacitance levels (i.e., ability to hold a charge) were 7 orders of magnitude greater for wind-blown sand. Figure 1 shows a comparatively tight dome distribution with mostly only larger grains falling past the edges of the pile. This is because electrostatic attraction generally holds the pile, especially the smaller particles, together. Figure 2 shows a statistical distribution of sizes from the two samples.

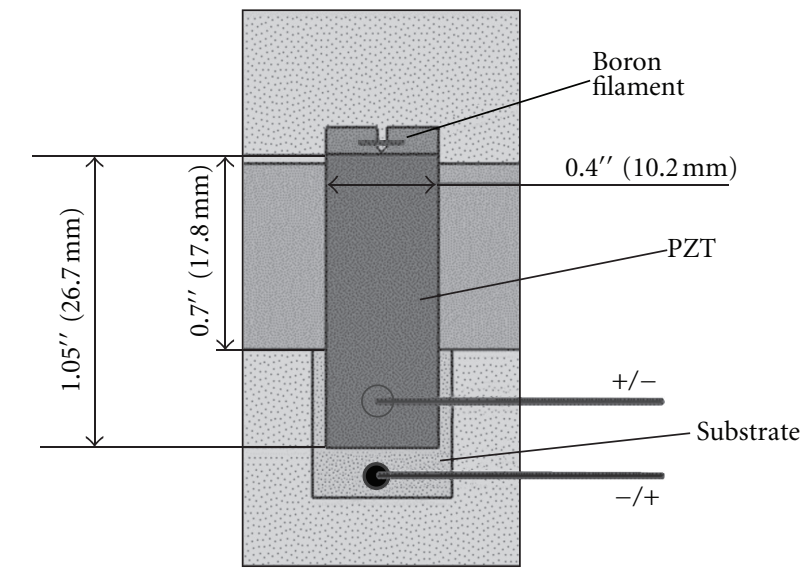

FIgUre 4: Piezoelectric cleaning device dimensions (in inches).

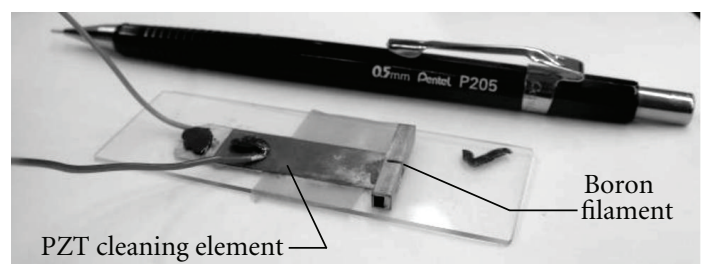

FIgUre 5: Assembled cleaning device.

The biggest challenge posed by windblown sand can be seen when compared to the physical size of an advanced AVS sensor element. Considering $1 \mathrm{~mm}$ long platinum sensor elements with a $5 \mu \mathrm{m} \times 200 \mathrm{~nm}$ cross-section, it is easy to see that the wide distribution of sizes of windblown sand presents not only a great threat of electrostatic cling, but physical entrapment between the filaments and the substrate itself. From Figure 3, it is easy to see that as air flows from lower left to upper right and back if it were bearing particles with size distributions laid out in Figure 2, serious challenges could be posed to the sensors. Figure 3 shows that the size of the desert sand goes well into the "dust" range with particles ranging down to fractions of a filament diameter, leading to cling of charged particles to filaments.

Because such atmospheric particles can render this remarkable sensor ineffective, this study is centered on making a system which can skirt these problems by effectively and safely cleaning the filaments of all foulants. References [3-5] highlight the point that there is relatively little in the open literature on infra-through-ultrasonic particle rejection known in the open literature. 


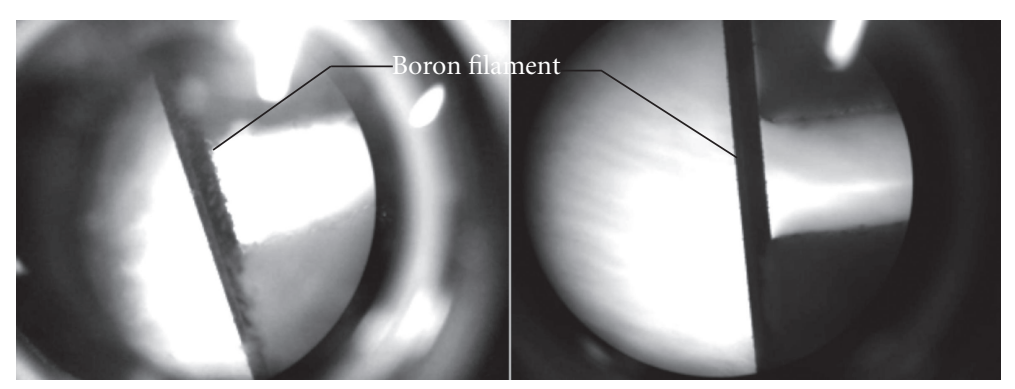

Figure 6: Boron fiber before and after cleaning with $20 \mathrm{kHz}$ ultrasonic vibrations.

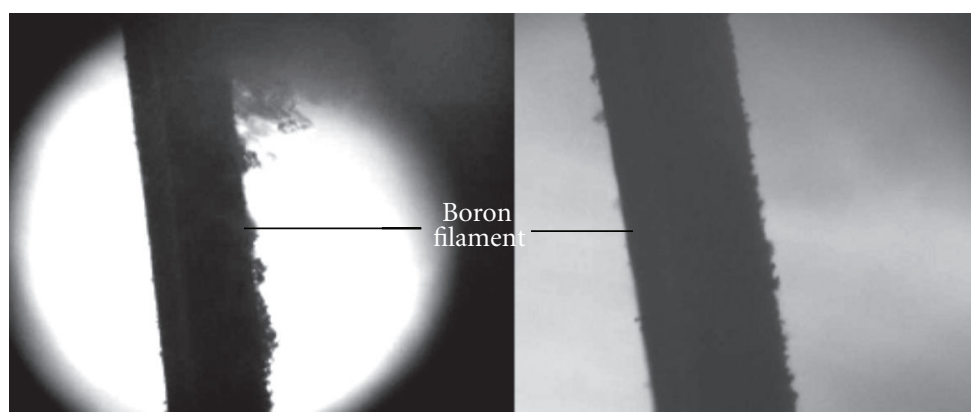

FIGURE 7: Boron fiber before and after cleaning—calibrated 5-30 $\mu \mathrm{m}$ diameter particles.

\section{Proof-of-Concept Testing on Boron Filaments}

The chosen method of cleaning the AVS sensor is to use piezoelectric elements to induce infrasonic, sonic, and ultrasonic vibrations to mechanically knock off particulate contaminants. As a proof-of-concept exercise, Lead-Zirconate Titanate (PZT) was designed into a "micro-shaker."

To test the concept in a variety of environments a range of filament diameters were chosen as well as a range of particle sizes. The first filament tested represented a large-scale an analog to the AVS sensor. A $127 \mu \mathrm{m}$ diameter boron fiber was fixed to a brass substrate and PZT extensional actuator element. The basic dimensions (in inches) of the device constructed are shown in Figure 4 and the finished device is shown in Figure 5. Teflon tape was used to allow for low friction longitudinal motion.

To observe the fiber, the assembled device was placed under a microscope. Excitation of the PZT strip was achieved using a signal generator and a linear voltage amplifier. Figure shows a fiber which was coated with $5-30 \mu \mathrm{m}$ diameter dust particles under the microscope before and after the PZT strip was excited. A $20 \mathrm{kHz}$ sine wave with a peak to peak voltage of $20 \mathrm{~V}$ was used to excite the PZT, generating local filament accelerations in excess of 350 g's. Although no deflections were visible during the cleaning event, the effect was pronounced.

Although not clearly visible in Figure 6, the dust used for the first test was microscopically fibrous in nature. Still, it possessed conductivity, capacitance levels and charge accretion properties which were within $20 \%$ of the Rub al Khali desert sand sample. Figure 7 shows the Boron fiber which had been dusted with nonfibrous silicate particles before and after cleaning. As with the fibrous foulants, the conductivity, capacitance levels and charge accretion properties which were within $20 \%$ of the Rub al Khali desert sand sample.

\section{Anemometer Wire Fouling and Cleaning}

It has been shown that debris can be successfully removed from a small diameter Boron filament using PZT to vibrate the wire. The following sections extend this result to a hot wire anemometer, which is more representative of AVS elements. Two different anemometers were constructed, one using a copper sensing wire and another using a nickel titanium alloy wire.

3.1. Nickel Titanium Alloy Filament Anemometer. Nickel titanium alloy (NiTinol) was used for the second type of anemometer constructed. This selection was chosen due to its ideally small diameter of only $38 \mu \mathrm{m}$. For this anemometer, copper-conducting posts were soldered to a circuit board and the NiTiNOL was fixed to the ends of the posts. Figure 8 shows the basic configuration of the NiTiNOL anemometer. The guide posts were later discarded when it was determined that they would not affect the results.

To vibrate the NiTiNOL anemometer, a small stand was built that supported a PZT bending element. The bending element consisted of PZT strips bonded to either side of an aluminum substrate. This configuration resulted in vertical deflections of the anemometer when the actuator is parallel to the ground. Figures 9 and 10 show the NiTiNOL filament mounted on the PZT bending element. 


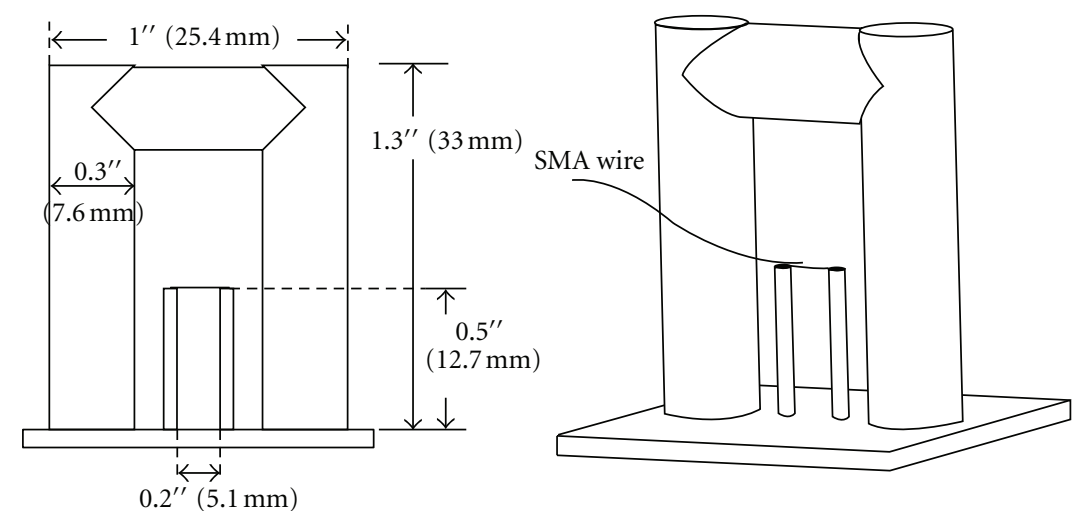

Figure 8: Nickel titanium alloy anemometer.

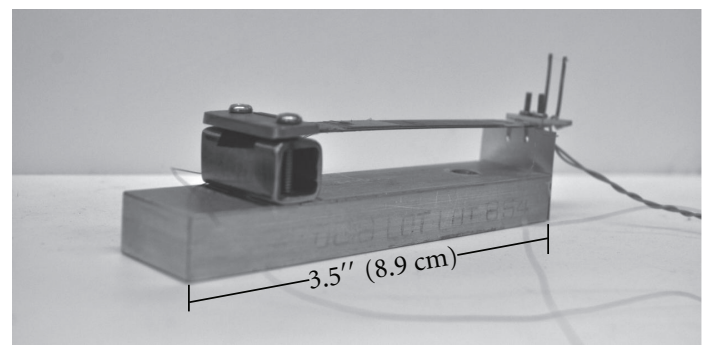

Figure 9: NiTiNOL anemometer mounted on PZT bending actuator.

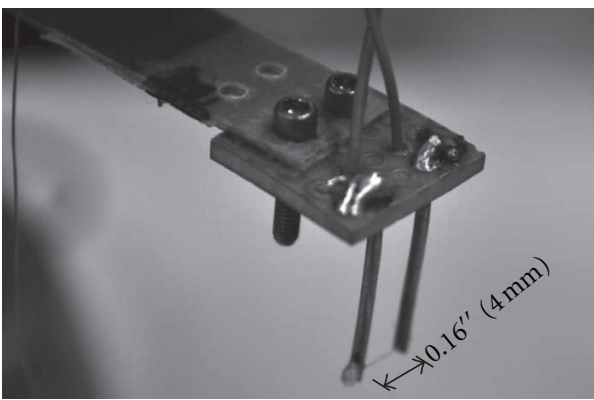

Figure 10: NiTiNOL anemometer.

3.2. Experimental Setup. A small blowdown type wind tunnel of $2^{\prime \prime}$ inner diameter was built to test the properties of the AVS cleaning system as shown in Figure 11. This setup provided a consistent airflow at a velocity of up to $4 \mathrm{~m} / \mathrm{s}$. Data was collected using a laptop computer with LABView data acquisition software. This was only used to record the time history of the resistance or current running through the anemometer.

A $1 \mathrm{~F}$ capacitor arranged in parallel with the power supply provided clean power. For the NiTiNOL tests, a constant voltage was applied across the circuit. Testing was conducted from 50 to $250 \mathrm{~mA}$ (with filament failure being experienced at $270 \mathrm{~mA}$. Current was measured by tracking voltage drop across a $1 \Omega$ power resistor as shown in Figure 12.

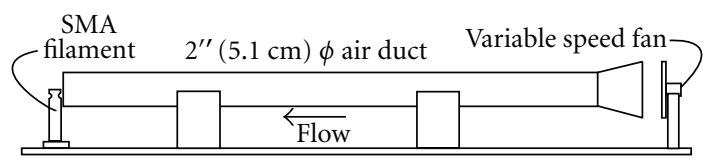

FIGURE 11: Wind tunnel setup.

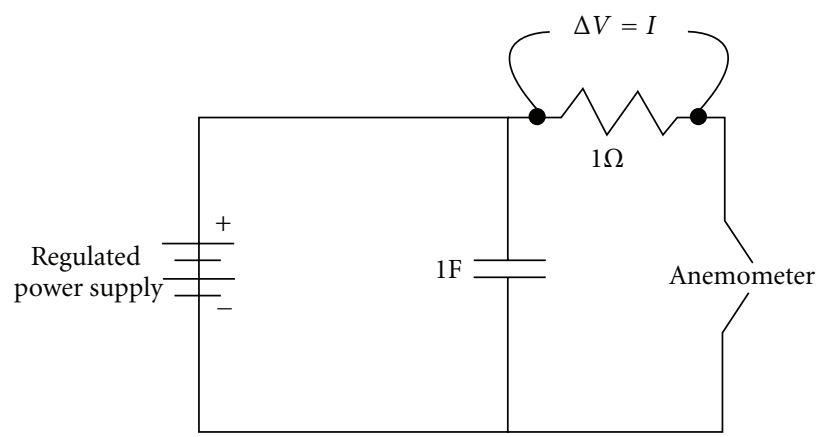

Figure 12: NiTiNOL anemometer circuit.

3.3. Baseline NiTiNOL Anemometer Testing and Results. As a baseline for the performance of the anemometer, the fan was cycled on and off several times without any cleaning excitation. The actuator was then excited at $200 \mathrm{~Hz}$ and the fan was cycled on and off again. Figure 13 shows the current flow through the filament during the fan cycles for the static and vibrating case. The peak voltage for the vibrating case drops a small amount during the cycles, but the amplitude of voltage change is approximately the same over each cycle. This indicates that the vibrations have little effect on the performance of the anemometer.

Figure 13 shows the overall peak-to-peak performance of the actuator by two phase shifted signals. The reader is asked to note that the measurements that are most important from Figure 13 are the peak-to-peak values and intermediate signal ripple, not the degree of phase shift.

After testing the performance of the clean anemometer, calibrated $5-30 \mu \mathrm{m}$ diameter nonfibrous dust was then applied to the wire and the performance was checked again. Figures 14, 15, and 16 show the resulting change in 


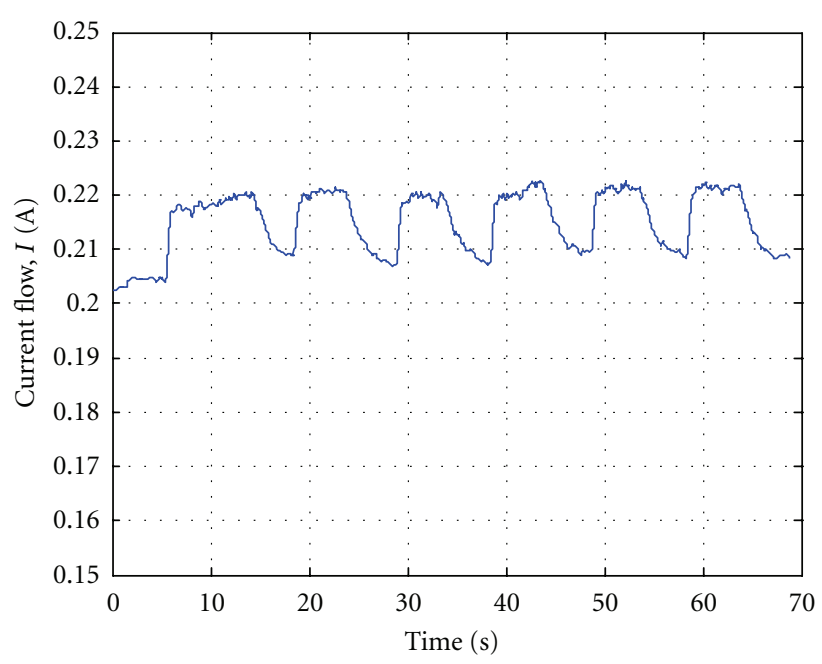

- Static

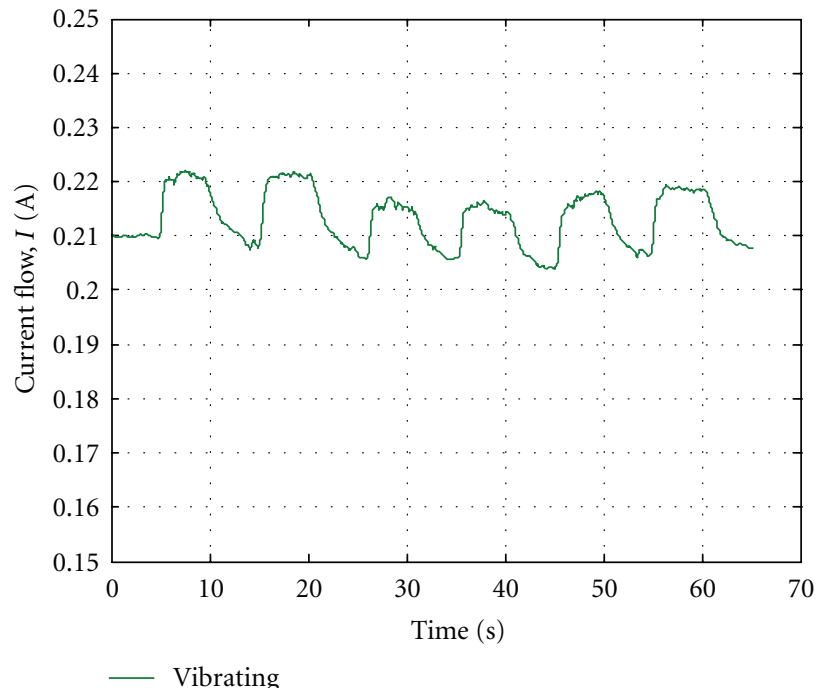

(b)

Figure 13: Baseline clean NiTiNOL anemometer before dusting.

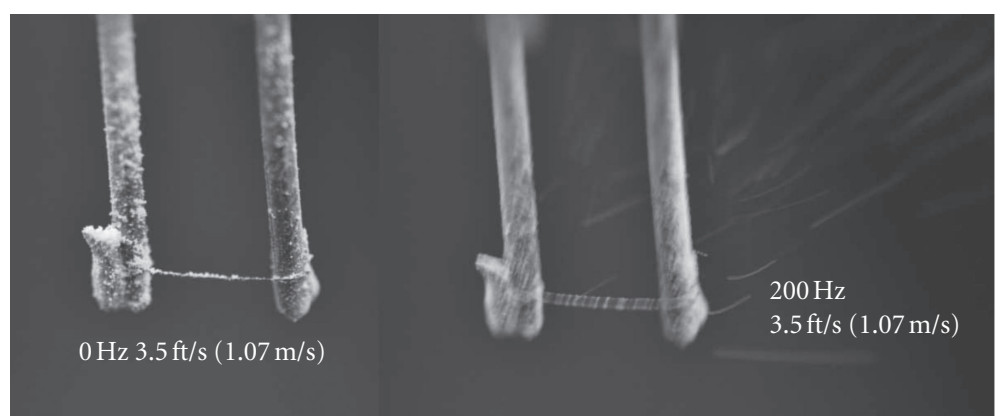

FIgURE 14: NiTiNOL anemometer filament dusted with 5-30 $\mu \mathrm{m}$ particles and under $200 \mathrm{~Hz}$ excitation (for photographic reference).

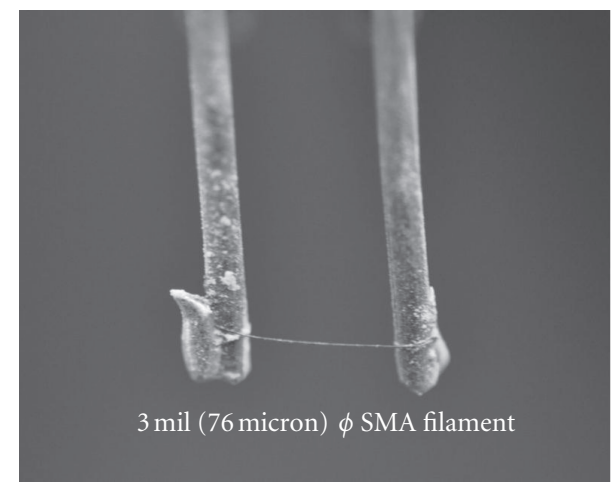

FIGURE 15: Anemometer after cleaning with infra-through ultrasonic vibrations.

performance for the anemometer. Each test was conducted in the following manner and order. Dusted, vibrating, and after cleaning refer to the curves in Figures 14, 15, and 16.

(1) Dusted: the calibrated $5-30 \mu \mathrm{m}$ diameter dust was applied and the fan was cycled on and off with out any vibration.

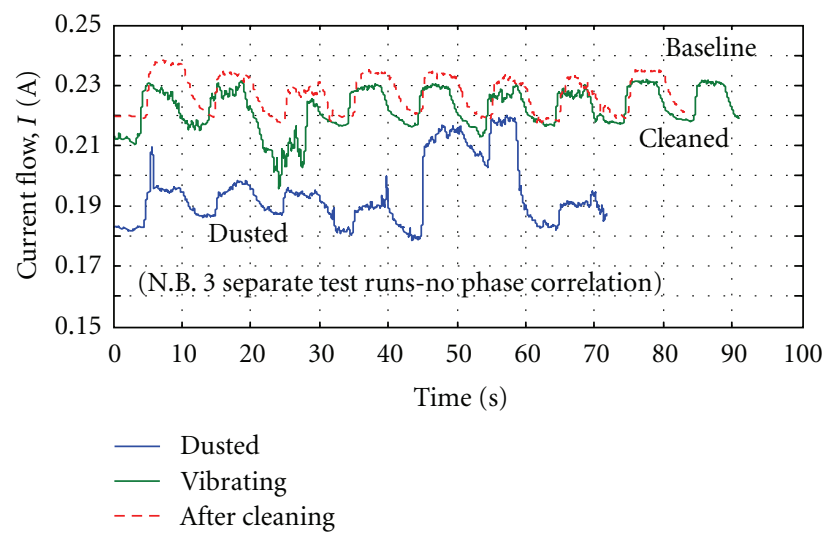

Figure 16: Baseline, dirty, and cleaned current flow through anemometer filament.

(2) Vibrating: the actuator was excited $(200 \mathrm{~Hz}$ at 7 Volts) and the fan was cycled on and off.

(3) After cleaning: the actuator was turned off and the fan was cycled on and off. 
Figures 14,15 , and 16 show the quiescent $38 \mu \mathrm{m}$ diameter NiTiNOL filament suspended between two support posts, covered with calibrated 5-30 $\mu \mathrm{m}$ diameter charged particles. Live testing of the cleaning system was conducted in a $4 \mathrm{~m} / \mathrm{s}$ airflow. Infrasonic through ultrasonic vibrations of 10 $20 \mathrm{kHz}$ clearly rejected electrostatically attached particles as shown in Figures 14, 15 and 16.

Clearly from Figure 16, it has been shown that fouled anemometer filaments generate highly erratic unreliable readings with current flow shifts on the order of $35 \mathrm{~mA}$. Given an anemometry sensitivity level on the order of $400 \mathrm{~m} / \mathrm{s} / \mathrm{A}$, this represents a signal corruption level of $14 \mathrm{~m} / \mathrm{s}$. Infrasonic through ultrasonic cleaning rejected such particulate fouling and resulting signal corruption, leading to restoration of performance levels to within $2 \%$ of baseline performance.

\section{Conclusions}

It has been shown that some of the most advanced microanemometer and acoustic vector sensor (AVS) elements are vulnerable to signal corruption when exposed to typical windblown particles. A statistical analysis of windblown desert sand from the Arabian Peninsula showed that statistically significant percentages of particles ranged from just 1/100th of the diameter of a typical AVS sensor filament to large enough to become lodged between the filaments and even between the filaments and mounting substrate. Wind tunnel tests on $38 \mu \mathrm{m}$ diameter filaments showed anemometry sensitivities on the order of $400 \mathrm{~m} / \mathrm{s} / \mathrm{A}$ were achieved. These sensitivities were dramatically corrupted when the filament was exposed to 5-30 $\mu \mathrm{m}$ diameter particles which were shown to electrostatically cling to the filament, junctions, and post. In addition to erratic signals due to dusting an erroneous shift resulting in a $14 \mathrm{~m} / \mathrm{s}$ measurement error appeared due to particulate fouling. An infra-through ultrasonic cleaning system was designed to reject these particles. When energized and swept through a broad frequency range, foulants were expelled from the sensor filaments, restoring sensor performance to within $2 \%$ of baseline levels.

\section{Acknowledgment}

The authors would like to thank the University of Kansas Transportation Research Institute for the continued support and funding of this and related research.

\section{References}

[1] D. R. Fulton, P. A. Hawes, and K. S. Lally, "Multiple Acoustic Threat Assessment System," International Patent Applcation No. PCT/US2009/039909.

[2] H. E. De Bree, "A perspective on acoustic vector sensors in passive surveillance-real world measurements, algorithms and applications," in Proceedings of the Aero India, Bangalore, India, 2009.

[3] D. Ensminger, Ultrasonics: Data, Equations, and Their Practical Uses, vol. 10, CRC Press, Boca Raton, Fla, USA, 2009.
[4] D. Williams, Guide to Cleaner Technoogies: Cleaning and Degreasing Process Changes, US Environmental Protection Agency (EPA), Washington, DC, USA, 1994.

[5] G. K. Nikas, "A mechanistic model of spherical particle entrapment in elliptical contacts," Proceedings of the Institution of Mechanical Engineers, Part J, vol. 220, no. 6, pp. 507-522, 2006. 

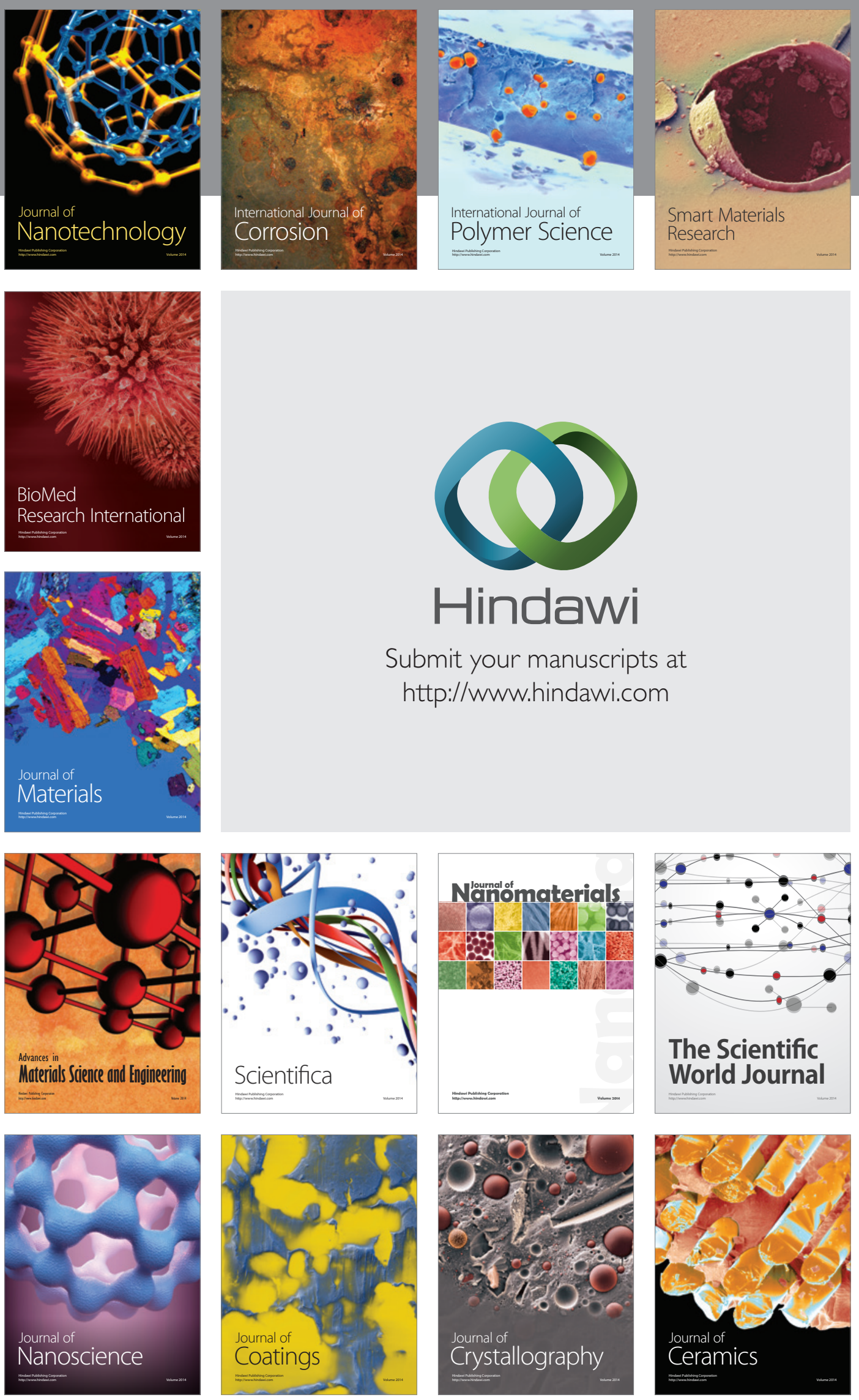

The Scientific World Journal

Submit your manuscripts at

http://www.hindawi.com

\section{World Journal}

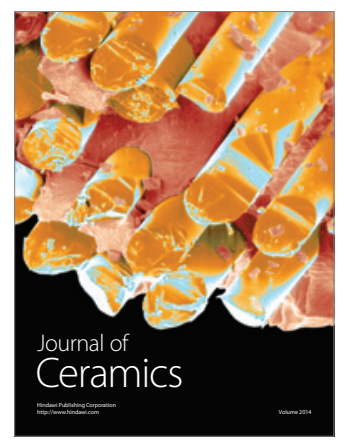

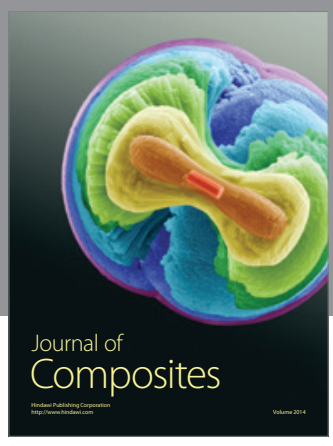
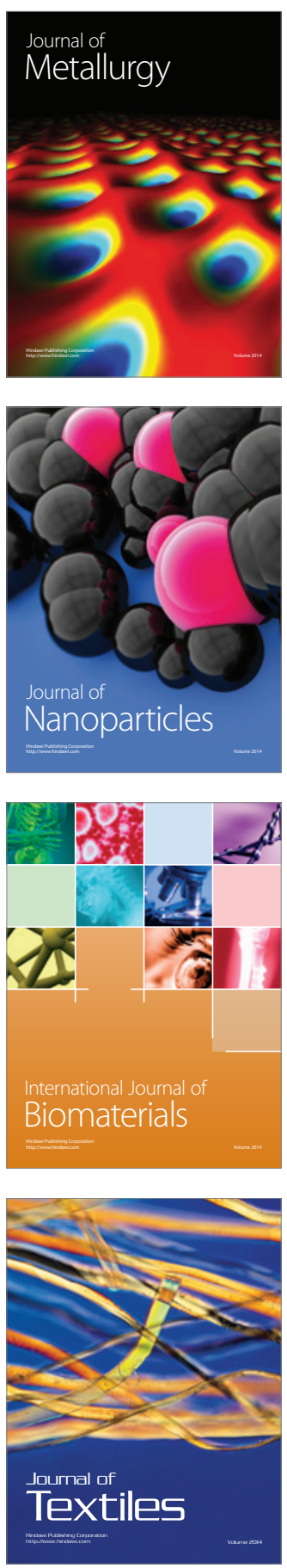